\title{
Hybrid repair of mitral paravalvular leak: Open surgical placement of a percutaneous occluder device
}

\author{
Alexander Kulik, MD, ${ }^{\text {a } M a r i n o ~ L a b i n a z, ~ M D, ~}{ }^{\mathrm{b}}$ Luc M. Beauchesne, MD, ${ }^{\mathrm{b}}$ Donna Nicholson, MD, ${ }^{\mathrm{c}}$ \\ and Pierre Bédard, MD, ${ }^{a}$ Ottawa, Ontario, Canada
}

$\mathrm{P}$

aravalvular leak (PVL) is a rare but serious complication of mitral valve replacement. ${ }^{1,2}$ Although PVLs have traditionally been repaired surgically, there has been a growing interest in the attempt to close PVLs through the use of percutaneous interventional techniques with occluder devices. ${ }^{3}$ Herein we report an innovative and multidisciplinary approach to the repair of a severe mitral PVL in a patient with aortic and mitral mechanical prostheses. Interventional techniques were not successful, and the intraoperative exposure of the anterolateral mitral PVL was extremely difficult because of the presence of the aortic prosthesis. To our knowledge, this is the first reported case of an open surgical placement of a percutaneous occluder device to repair a mitral paraprosthetic leak.

\section{Clinical Summary}

A 58-year-old man presented with pulmonary edema and an apical pansystolic murmur. Seventeen years earlier, he had undergone aortic and mitral valve replacement with MedtronicHall prostheses (aortic prosthesis size 25; mitral prosthesis size 33; Medtronic Inc, Minneapolis, Minn) for rheumatic valve disease. Clinical and laboratory evaluation revealed no evidence of endocarditis or hemolysis. Echocardiography demonstrated mild left ventricular dysfunction and normally functioning aortic and mitral prostheses. However, there was a severe $(4+)$ PVL originating at the anterolateral section of the mitral prosthesis measuring $5 \mathrm{~mm}$ in width (Figure 1). Subsequently, an attempt was made at closing the mitral PVL with percutaneous techniques. Despite the use of numerous catheters and multiple attempts, a guide wire could not be passed through the paravalvular defect. The patient was therefore referred for surgical repair of the PVL.

Given the presence of an aortic prosthesis and the location of the PVL at the anterolateral commissure, it was anticipated that surgical exposure for direct suture repair would be very difficult, especially through a median sternotomy. Therefore a decision was made to perform a right thoracotomy to optimize mitral valve exposure. Should adequate exposure of the PVL be unattainable, then the cardiology team would deploy a percutaneous occluder device through the open surgical wound to close the PVL.

From the Divisions of Cardiac Surgery, ${ }^{\mathrm{a}}$ Cardiology, ${ }^{\mathrm{b}}$ and Cardiac Anesthesia, ${ }^{c}$ University of Ottawa Heart Institute, Ottawa, Ontario, Canada.

Received for publication July 25, 2006; accepted for publication Aug 8, 2006.

Address for reprints: Pierre Bédard, MD, University of Ottawa Heart Institute, 40 Ruskin St, Suite H3205, Ottawa, Ontario K1Y 4W7, Canada (E-mail: pbedard@ ottawaheart.ca).

J Thorac Cardiovasc Surg 2006;132:1469-70

$0022-5223 / \$ 32.00$

Copyright $\odot 2006$ by The American Association for Thoracic Surgery doi:10.1016/j.jtcvs.2006.08.022

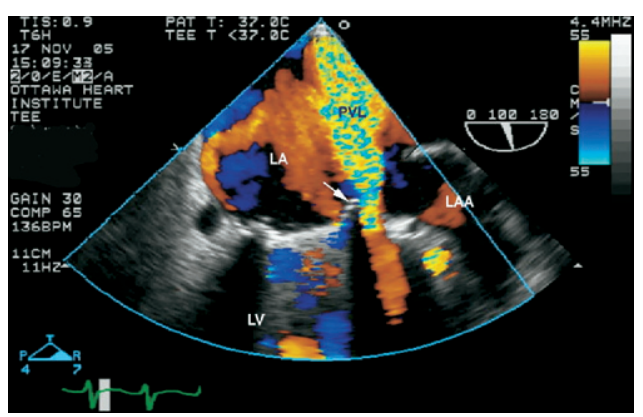

Figure 1. Preoperative transesophageal echocardiogram still frame illustrating a severe $(4+)$ paravalvular leak at the anterolateral edge of the sewing ring of the mitral prosthesis (arrow). $L A$, Left atrium; $L A A$, left atrial appendage; $L V$, left ventricle; $P V L$, paravalvular leak.

During the operation, exposure of the aorta proved difficult through the thoracotomy incision, necessitating left femoral artery cannulation. Bicaval cannulation was performed, the patient was cooled to $25^{\circ} \mathrm{C}$, and circulatory arrest was achieved for a total of 14 minutes. The left atrium was opened, but the mitral valve exposure was extremely challenging given the presence of the aortic prosthesis. Although the PVL could not be seen directly, it could be probed with a right-angle dissector slightly above the anterolateral commissure. Surgical repair was believed to be impossible without rereplacement of the mitral valve. Therefore a 10-mm Amplatzer muscular ventricular septal defect occluder device (AGA Medical Corp, Golden Valley, Minn) was navigated under the edge of the aortic prosthesis and through the mitral PVL and deployed successfully. The circulation was subsequently restarted while the left atrium was closed, and the patient was warmed. The cardiopulmonary bypass time was 114 minutes.

A transesophageal echocardiogram after cardiopulmonary bypass revealed a mild residual PVL (Figure 2). The device did not interfere with disc motion of the mitral or aortic prostheses. The patient had an unremarkable postoperative course and was discharged home on postoperative day 10 . One month after the operation, the patient was active and completely asymptomatic. The follow-up transthoracic echocardiogram at that time continued to show a mild residual PVL.

\section{Discussion}

PVL is defined as an abnormal retrograde flow of blood around the circumference of a prosthetic valve between the sewing ring and the annulus of the native valve. ${ }^{1}$ The incidence of mitral PVL has been reported to be between $0.1 \%$ and $1.4 \%$ per patient-year, ${ }^{1,2}$ with more than $75 \%$ of PVLs seen around the commissural areas. ${ }^{4}$ Although the exact cause is not always clear, PVL is thought to 


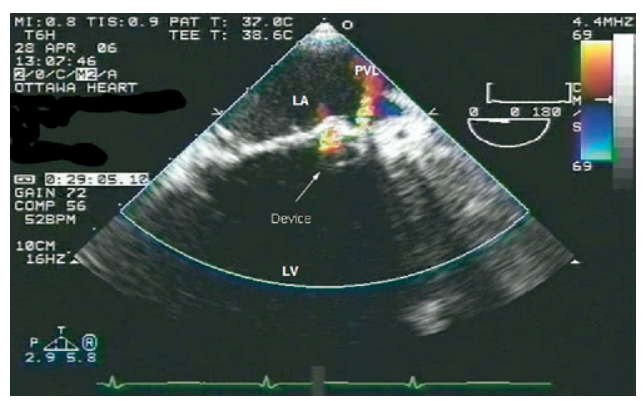

Figure 2. Intraoperative transesophageal echocardiogram still frame illustrating a well-deployed low-profile device (arrow). There is a mild $(1+)$ residual paravalvular leak. $L A$, Left atrium; $L V$, left ventricle; $P V L$, paravalvular leak.

occur as a result of gradual weakening of annular tissue, deterioration of suture material, technical mistakes, or acute infection. ${ }^{1}$ Surgical intervention to repair the leak improves symptoms of heart failure, decreases the need for blood transfusion, and is an independent predictor of long-term survival when compared with medical therapy alone. ${ }^{2,5}$ The choice of operation involves either direct suture repair of the PVL or rereplacement of the valve and is indicated to correct worsening left ventricular function or symptoms of heart failure and hemolysis. ${ }^{1}$

Although surgical intervention has been the gold standard for the repair of PVLs, there has been a growing interest in the attempt to close PVLs through the use of interventional cardiologic techniques. Several reports have documented the successful percutaneous repair of PVLs with closure devices similar to those applied for the percutaneous treatment of septal defects. ${ }^{3}$ Percutaneous closure has several advantages, including the elimination of the risk of a redo operation and shortening the length of hospital stay. Nevertheless, the procedure is complex, time consuming, and not always successful, as illustrated in this case. Successful intraoperative device closure of muscular ventricular septal defects has previously been reported. ${ }^{6}$ However, to our knowledge, the case presented herein is the first reported use of the intraoperative placement of a percutaneous occluder device for the surgical repair of a PVL. This novel approach for the repair of a mitral PVL can be applied in the context of extremely difficult mitral prosthesis exposure, such as the presence of a concurrent aortic prosthesis, or to avoid lengthy redo operations in very high-risk patients.

\section{References}

1. Kirali K, Mansuroglu D, Yaymaci B, Omeroglu SN, Basaran Y, Ipek G, et al. Paravalvular leakage after mitral valve replacement: is left atrial enlargement an additional indication for reoperation? J Heart Valve Dis. 2001;10:418-25.

2. Akins CW, Bitondo JM, Hilgenberg AD, Vlahakes GJ, Madsen JC, MacGillivray TE. Early and late results of the surgical correction of cardiac prosthetic paravalvular leaks. J Heart Valve Dis. 2005;14:792-800.

3. Pate GE, Thompson CR, Munt BI, Webb JG. Techniques for percutaneous closure of prosthetic paravalvular leaks. Catheter Cardiovasc Interv. 2006;67:158-66.

4. Genoni M, Franzen D, Tavakoli R, Seiffert B, Graves K, Jenni R, et al. Does the morphology of mitral paravalvular leaks influence symptoms and hemolysis? J Heart Valve Dis. 2001;10:426-30.

5. Genoni M, Franzen D, Vogt P, Seifert B, Jenni R, Kunzli A, et al Paravalvular leakage after mitral valve replacement: improved long-term survival with aggressive surgery? Eur J Cardiothorac Surg. 2000;17:14-9.

6. Bacha EA, Cao QL, Starr JP, Waight D, Ebeid MR, Hijazi ZM. Perventricular device closure of muscular ventricular septal defects on the beating heart: technique and results. J Thorac Cardiovasc Surg. 2003; 126:1718-23.

\section{Feasibility of preservation of subvalvular apparatus in mitral valve replacement with the $0 n-X$ mechanical valve}

Hiroshi Tanaka, MD, Teruo Yamshita, MD, Kenji Okada, MD, Keitaro Nakagiri, MD, Yujiro Kawanishi, MD, and Yutaka Okita, MD, Kobe, Japan

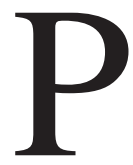

reserving subvalvular apparatus in mitral valve replacement brings a significant long-term advantage by preserving left ventricular function. The possibility of prosthetic valve entrapment of the retained subvalvular apparatus, left

From Kobe University Hospital, Department of Cardiovascular, Thoracic, and Pediatric Surgery, Kobe, Japan.

Received for publication July 15, 2006; accepted for publication Aug 8, 2006.

Address for reprints: Hiroshi Tanaka, MD, Kobe University Hospital, Department of Cardiovascular, Thoracic, and Pediatric Surgery, 7-5-2, Kusunoki-cho, Chuo-ku, Kobe, Japan (E-mail: hirot@ams.odn.ne.jp).

J Thorac Cardiovasc Surg 2006;132:1470-1

$0022-5223 / \$ 32.00$

Copyright (C) 2006 by The American Association for Thoracic Surgery doi:10.1016/j.jtcvs.2006.08.030 ventricular outflow tract obstruction, and implantation of a smallersized prosthesis has been of major concern to investigators advocating this procedure. Recently introduced, the On-X mechanical valve (Medical Carbon Research Institute, Austin, Tex) has the advantage of reduced anticoagulation and a specific structure of leaflet flare for protection from retained subvalvular apparatus and pannus encroachment. We operated on 6 patients requiring mitral valve replacements using the On-X mechanical mitral valve and obtained good results without complications associated with this procedure.

\section{Clinical Summary}

From October 2005 to March 2006, 6 patients underwent mitral valve replacement for mitral valve stenosis using the On-X mitral valves with the techniques of preserving mitral papillary muscle continuity. 